\title{
Enterotoxins, colonization factors, serotypes and antimicrobial resistance of enterotoxigenic Escherichia coli (ETEC) strains isolated from hospitalized children with diarrhea in Bolivia
}

Authors

Claudia Rodas ${ }^{1}$

Rosalía Mamani ${ }^{2}$

Jorge Blanco 3

Jesus Eulogio Blanco ${ }^{3}$

Gudrun Wiklund ${ }^{4}$

Ann-Mari Svennerholm ${ }^{5}$

Åsa Sjöling 5

Volga Iniguez ${ }^{6}$

${ }^{1} \mathrm{MSc}$, Microbiology; $\mathrm{PhD}$

student, Department

of Microbiology and

Immunology, Institute of

Biomedicine, University of

Gothenburg, Sweden.

${ }^{2} \mathrm{MsC}$, Bioscience; $\mathrm{PhD}$

student, Laboratorio de

Referencia de Escherichia

coli, Departamento de

Microbiología y Parasitología

Universidad de Santiago de

Compostela, Lugo, Spain

${ }^{3} \mathrm{Dr}$., $\mathrm{PhD}$, WHO

Collaborating Centre for

Reasearch on ETEC and

Department of Microbiology

and Immunology, Institute

of Biomedicine, University of

Gothenburg, Sweden

${ }^{4} \mathrm{MSc}$, WHO Collaborating

Centre for Reasearch on

ETEC and Department

of Microbiology and

Immunology, Institute of

Biomedicine, University of

Gothenburg, Sweden

${ }^{5} \mathrm{MD}$, Professor, WHO

Collaborating Centre for

Reasearch on ETEC and

Department of Microbiology

and Immunology, Institute

of Biomedicine, University of

Gothenburg, Sweden

${ }^{6} \mathrm{Dr}$., PhD, Intituto de Biología

Molecular y Biotecnología

Facultad de Ciencias Puras y

Naturales, Universidad Mayor

de San Andrés, Bolivia

Submitted on: 08/11/2010 Approved on: 09/27/2010

Correspondence to:

Claudia Rodas

Department of

Microbiology and

Immunology,

Institute of Biomedicine,

University of Gothenburg,

Box 435, 40530

Gothenburg, Sweden.

Phone: +46-31-7866233

Fax: +46-317866205

claudia.rodas@

microbio.gu.se

We declare no conflict of interest.

\begin{abstract}
Enterotoxigenic Escherichia coli (ETEC) is recognized as the main cause of bacterial diarrhoea among children in Asia, Africa and Latin America but less investigated in Bolivia. Objective: To determine the relation between enterotoxins, CFs and serotypes as well as the antimicrobial resistance patterns in a set of ETEC isolates collected from hospitalized children with acute diarrhea. In the present study we characterized 43 ETEC strains isolated from 2002 to 2006 from hospitalized children (0-5 years) with acute diarrhea in Bolivia. The strains were analyzed for heat-labile (LT) and heat-stable (ST) enterotoxins and colonization factor (CF) profiles, as well as for serogroups and antimicrobial resistance using phenotypic (ELISA, dot blot, slide agglutination and disc diffusion) and genotypic (Multiplex PCR) methods. Among the ETEC isolates tested, 30 were positive for LT, 3 for STh and 10 for LT/STh. Sixty-five percent (28/43) of the strains expressed one or more CF. The most common CFs were CS17 $(n=8)$ and CFA/I $(n=8)$. The phenotypical and genotypical results for toxins and CFs were congruent except for CS21 that was amplified in 10 of the strains by multiplex PCR, but CS21 pili was only detected phenotypically in four of these strains. The ETEC strains had diverse $\mathrm{O}$ and $\mathrm{H}$ antigens and the most common types were O8:H9 LT CS17 $(\mathrm{n}=6 ; 14 \%)$ and O78:HNM LT-ST CFA/I $(\mathrm{n}=4 ; 9 \%)$. The analysis of antibiotic resistance showed that $67 \%(n=29 / 43)$ of the strains were resistant to one or several of the antimicrobial agents tested. Presence of CFs was associated with antibiotic resistance. Conclusion: The most common toxin profile was LT 70\%, LT/STh 23\% and STh 7\%. High antimicrobial resistance to ampicillin among serogroups $\mathrm{O} 6, \mathrm{O} 8$ and $\mathrm{O} 78$ were the most common.
\end{abstract}

Keywords: enterotoxigenic Escherichia coli; enterotoxins; drug resistance; Bolivia.

[Braz J Infect Dis 2011;15(2):132-137]@Elsevier Editora Ltda.

\section{INTRODUCTION}

Acute diarrheal diseases are an important health problem among children under five in developing countries and annually cause between 1.4 to 2.5 million deaths. ${ }^{1,2}$ Diarrheal diseases cause high rates of pediatric morbidity and mortality in Bolivia, leading annually to more than 500,000 cases and between 13,000 and 15,000 deaths respectively. ${ }^{3}$ Enterotoxigenic Escherichia coli (ETEC) is an important cause of diarrhea among children in developing countries and among travelers to ETEC-endemic areas. ${ }^{4}$ Clinical human ETEC isolates produce one or more of three enterotoxins; the heat stable toxins (STp and STh) and heat labile toxin (LT) and may produce one or more of several colonization factors (CFs). ${ }^{5}$ The CFs mediate adherence to the small intestinal mucosa, and to date, more than 22 different CFs have been described in human ETEC strains (e.g CFA/I, CS1-CS8, CS12-CS15, and CS17-CS22). ${ }^{5-8}$ In developing countries, the incidence of ETEC-associated diarrhea decreases during the first five years of life ${ }^{9}$ whereas children and adults from industrialized areas who travel to these countries are susceptible to this type of diarrhea, indicating that natural immunity develops. ${ }^{4,10}$

The LT enterotoxin and the CF antigens are immunogenic and hence the main candidates for vaccines that are being developed against ETEC diarrhea. ${ }^{10,11}$ Since ETEC strains have diverse toxin, $\mathrm{CF}$ and serogroup profiles it is important to characterize clinical ETEC isolates from different parts of the world with respect to virulence profiles to evaluate the impact that different vaccine compositions could have on ETEC diarrhea. Moreover, antibiotic 
resistance among ETEC strains is increasing, perhaps due to indiscriminate use of antibiotics. Although rehydration therapy is the most important part of therapy for acute diarrhea, antimicrobials are important adjuvants for therapy and their use results in a marked decrease in overall stool volume and decreased length of illness. Most cases of bacterial gastroenteritis are self-limiting and in otherwise healthy patients, administration of antibiotics is not necessary. However in infants, elderly people, granulocytopenic or immunodepressed patients with enteritis, and for patients with extra-intestinal infections, particularly when bacteremia is suspected, antibiotic therapy is fundamental for disease control. ${ }^{12}$ The knowledge of antimicrobial resistance patterns locally in different countries is important when prescribing antibiotics for diarrheagenic bacteria, and can serve as a guide for implementing public health interventions against diarrheal disease.

In this study, we determined the relation between enterotoxins, CFs and serotypes, as well as the antimicrobial resistance patterns in a set of ETEC isolates collected from hospitalized children with acute diarrhea.

\section{MATERIAL AND METHODS}

\section{Bacterial strains and determination of toxins and CFs}

ETEC strains were isolated from acute watery non-bloody stool samples obtained from hospitalized children with diarrhea under five years of age in La Paz, Bolivia, between 2002-2006. ETEC strains were grown on MacConkey agar plates, incubated at $37^{\circ} \mathrm{C}$ for 18 hours and five lactose positive colonies were tested for the presence of ETEC toxins and CFs by GM1 ELISA, toxin multiplex PCR and dot blot. ${ }^{13}$ Confirmed ETEC strains were stored at $-70^{\circ} \mathrm{C}$ in Luria broth (Difco) containing 25\% glycerol and subsequently shipped to Sweden on deep agar stabs. All strains were re-analyzed twice by toxin GM1-ELISA, dot blot and Multiplex PCR in Sweden. ${ }^{13,14}$ For the dot blot the MAbs used were CFA/I, CS1 to CS6, CS8, CS12, CS14, CS17, CS19 and CS21. From the original set of ETEC strains $(n=79)$, we analyzed 43 ETEC strains that survived the transport, had identical toxin and CF profiles when tested both in Bolivia, Spain and Sweden and that were not mixed infections for serotype and antimicrobial resistance.

\section{Serotyping}

$\mathrm{O}$ - and $\mathrm{H}$-antigens were determined according to the method described by Guinée et al. ${ }^{15}$ and employing all available $\mathrm{O}(\mathrm{O} 1-\mathrm{O} 185)$ and $\mathrm{H}$ (H1-H56) antisera in the E. coli Reference laboratory (LREC) at the Universidad of Santiago de Compostela, Lugo, Spain. All antisera were obtained and absorbed with the corresponding cross-reacting antigens to remove nonspecific agglutinins. The $\mathrm{O}$ antisera were produced in the LREC and the $\mathrm{H}$ antisera were obtained from the Stat- ens Serum Institute (Copenhagen, Denmark). Isolates that did not react with any of the $\mathrm{O}$ and $\mathrm{H}$ antisera used were classified as non-typeable (ONT and HNT), and those that were non-motile were denoted HNM. ${ }^{16}$

\section{Antimicrobial resistance}

Colonies from McConkey agar cultures were homogenized in $0.85 \%$ saline, and the turbidity was adjusted to that of a $0.5 \mathrm{McF}$ arland standard. The inoculum suspension was spread on a Mueller-Hinton agar plate surface with a swab, and incubated in room temperature for $15 \mathrm{~min}$ before antimicrobial disks were applied. The antimicrobials tested were ampicillin, nalidixic acid, chloramphenicol, ampicillin-sulbactam, tetracycline, ciprofloxacin, trimethoprimsulfamethoxazole, gentamicin, and cefoxitin. The bacterial cultures were incubated for 20 hours at $37^{\circ} \mathrm{C}$, and the zone of inhibition was determined. The National Committee for Clinical Laboratory Standards ${ }^{17}$ breakpoints were used to differentiate between susceptible and resistant isolates. E. coli ATCC 25922 was used as a reference strain for quality control purposes.

\section{Statistics}

The two-tailed Fishers' exact test was used for statistical analysis using the GraphPad InStat Software and a 2 x 2 contingency table. A p-value less than 0.05 was considered significant.

\section{RESULTS}

ETEC strains were obtained from a prospective study in children under five years of age seeking care in three different hospitals in La Paz, Bolivia during 2002-2006. The children all suffered from non-bloody, acute diarrhea. In total, 853 clinical samples were analyzed and ETEC was isolated from 79 patients. Forty-tree individual ETEC strains isolated from watery non-bloody diarrhea samples with only one microbial pathogen isolated and with confirmed enterotoxin and CF expression in La Paz, Santiago de Compostela and Gothenburg were selected for further studies (Table 1).

The most common toxin profile among the selected strains was LT in 30 strains (70\%), followed by LT/STh in 10 strains (23\%) and STh in three strains (7\%). The presence of STp was not recorded in Bolivia and when analyzed for STp in Sweden and in Spain none of the strains harbored this toxin.

The CFs in the selected strains were analyzed both by multiplex PCR ${ }^{14}$ and dot blot. ${ }^{13}$ Overall, $65 \%$ (28/43) of the ETEC strains expressed one or more of the 19 CFs analyzed in multiplex PCR and results were corroborated by the phenotypic analyses and all cases except for CS21. The CFs found in the strains were CFA/I $(\mathrm{n}=8)$ and CS17 $(\mathrm{n}=8)$, $\mathrm{CS} 1+\operatorname{CS} 3(\mathrm{n}=3), \operatorname{CS} 2+\operatorname{CS} 3(\mathrm{n}=3)$, and $\operatorname{CS} 12(\mathrm{n}=3)$, and CS7 $(n=2)$, and CS6 $(n=1)$. CS21 was often found in 
Table 1. Characterized ETEC strains collected from Bolivian children with diarrhea

\begin{tabular}{|c|c|c|c|c|c|c|c|}
\hline \multirow[t]{2}{*}{ Strain } & \multicolumn{4}{|c|}{ Children } & \multicolumn{3}{|c|}{ Characteristics of strains } \\
\hline & Patient ID & Age & Sex & Toxin & $\mathrm{CFs}^{\mathrm{a}}$ & Serotype $^{b}$ & Antibiotic resistance $e^{\mathrm{c}, \mathrm{d}, \mathrm{e}}$ \\
\hline 1 & 9 & $18 \mathrm{~m}$ & $\mathrm{~F}$ & LTSTh & CFA/I CS21 & O1:H45 & AMP, SAM, TET \\
\hline 2 & 18 & $15 \mathrm{~m}$ & M & LT & CS17 & O8:H9 & AMP, CHL , SAM \\
\hline 3 & 19 & $3 \mathrm{~m}$ & M & LT & CS17 & O8:H9 & AMP, CHL , SAM, TET \\
\hline 4 & 34 & $18 \mathrm{~m}$ & $\mathrm{~F}$ & LTSTh & CS1 CS3 CS21 & O6:H16 & AMP, SAM , SXT \\
\hline 5 & 95 & $47 \mathrm{~m}$ & $\mathrm{~F}$ & LT & CS2 CS3 (CS21) & O21:HNT & - \\
\hline 6 & 98 & $13 \mathrm{~m}$ & M & LT & CS2 CS3 & O21: HNT & AMP, CHL TET, SXT, GEN \\
\hline 7 & 100 & $48 \mathrm{~m}$ & $\mathrm{~F}$ & LT & - & O120:H10 & - \\
\hline 8 & 104 & $9 \mathrm{~m}$ & $\mathrm{~F}$ & LT & - & O174:H40 & TET \\
\hline 9 & 110 & $12 \mathrm{~m}$ & $\mathrm{~F}$ & LT & - & ONT:HNM & nt \\
\hline 10 & 119 & $11 \mathrm{~m}$ & $\mathrm{~F}$ & LT & CS17 & O6:H9 & AMP, CHL , SAM \\
\hline 11 & 121 & $11 \mathrm{~m}$ & M & LT & CS17 & O8:H9 & AMP, CHL , SAM \\
\hline 12 & 124 & $9 \mathrm{~m}$ & M & LT & CS12 & O159: H4 & AMP, TET, SXT \\
\hline 13 & 126 & $17 \mathrm{~m}$ & $\mathrm{M}$ & LT & - & O41:H32 & - \\
\hline 14 & 132 & $14 \mathrm{~m}$ & M & LT & CS17 & O8:H9 & AMP, SAM , CHL \\
\hline 15 & 134 & $24 \mathrm{~m}$ & $\mathrm{~F}$ & LT & CS17 & O8:H9 & AMP, SAM , SXT \\
\hline 16 & 137 & $12 \mathrm{~m}$ & $\mathrm{~F}$ & STh & CS6 (CS21) & O148: H28 & AMP, SAM , SXT \\
\hline 17 & 162 & $14 \mathrm{~m}$ & $\mathrm{M}$ & LT & CS17 & O6: H16 & AMP, SAM \\
\hline 18 & 172 & $14 \mathrm{~m}$ & $\mathrm{M}$ & LT & - & O120:H10 & - \\
\hline 19 & 174 & $4 \mathrm{~m}$ & $\mathrm{~F}$ & LTSTh & - & O8:H9 & - \\
\hline 20 & 191 & $16 \mathrm{~m}$ & $\mathrm{M}$ & LT & - & ONT:H40 & TET \\
\hline 21 & 193 & $19 \mathrm{~m}$ & $\mathrm{~F}$ & LTSTh & CFA/I (CS21) & O78:HNM & AMP, SAM , SXT \\
\hline 22 & 204 & $11 \mathrm{~m}$ & $\mathrm{~F}$ & LT & - & O8:H9 & AMP, SAM \\
\hline 23 & 207 & $5 \mathrm{~m}$ & $\mathrm{M}$ & STh & CFA/I & O153: H45 & AMP, SAM , TET \\
\hline 24 & 220 & $16 \mathrm{~m}$ & $\mathrm{M}$ & LT & CS7 & O114:H49 & TSX \\
\hline 25 & 226 & $28 \mathrm{~m}$ & $\mathrm{~F}$ & LT & CS7 & O78: H10 & AMP, SAM , SXT \\
\hline 26 & 235 & $14 \mathrm{~m}$ & $\mathrm{M}$ & STh & CFA/I CS21 & ONT:HNM & AMP, SAM , TET \\
\hline 27 & 237 & $24 \mathrm{~m}$ & $\mathrm{~F}$ & LT & - & ONT:H40 & - \\
\hline 28 & 241 & $7 \mathrm{~m}$ & $\mathrm{M}$ & LT & - & ONT:HNM & AMP, SAM , SXT \\
\hline 29 & 244 & $18 \mathrm{~m}$ & $\mathrm{~F}$ & LTSTh & CFA/I (CS21) & O78:HNM & AMP \\
\hline 30 & 245 & $36 \mathrm{~m}$ & $\mathrm{~F}$ & LT & - & ONT:H40 & - \\
\hline 31 & 389 & $9 \mathrm{~m}$ & $\mathrm{M}$ & LTSTh & CS1 CS3 CS21 & O6:H16 & AMP, NAL, SXT \\
\hline 32 & 390 & $9 \mathrm{~m}$ & $\mathrm{~F}$ & LTSTh & CFA/I (CS21) & O78:HNM & - \\
\hline 33 & 409 & $9 \mathrm{~m}$ & $\mathrm{M}$ & LTSTh & CFA/I & O6:H16 & AMP, NAL, SAM , SXT \\
\hline 34 & 475 & $5 \mathrm{~m}$ & M & LT & CS1 CS3 & ONT:H40 & - \\
\hline 35 & 520 & $12 \mathrm{~m}$ & M & LT & - & ONT: HNM & AMP. SAM , TET \\
\hline 36 & 536 & $17 \mathrm{~m}$ & $\mathrm{M}$ & LT & - & O34:H25 & AMP, SAM , TET, SXT, GEN, CEF \\
\hline 37 & 554 & $17 \mathrm{~m}$ & $\mathrm{~F}$ & LT & - & O159:H4 & - \\
\hline 38 & 574 & $19 \mathrm{~m}$ & M & LT & - & ONT:HNM & - \\
\hline 39 & 577 & $36 \mathrm{~m}$ & $\mathrm{~F}$ & LT & CS17 & O8:H9 & AMP, SAM , TET, SXT \\
\hline 40 & 598 & $14 \mathrm{~m}$ & $\mathrm{~F}$ & LTSTh & CFA/I (CS21) & O78:HNM & - \\
\hline 41 & 631 & $17 \mathrm{~m}$ & $\mathrm{M}$ & LT & CS12 & O159:H21 & AMPS, TET, SXT \\
\hline 42 & 689 & $6 \mathrm{~m}$ & M & LTSTh & CS2 CS3 & $\mathrm{O} 1$ & AMP, SAM \\
\hline 43 & 743 & $12 \mathrm{~m}$ & $\mathrm{~F}$ & LT & CS12 & O159:H4 & - \\
\hline
\end{tabular}

${ }^{\mathrm{a} C S} 21$ within brackets is positive in PCR but negative in dot blot.

bNT, non typeable; HNM, non-motile.

cResistant to AMP, ampicillin; SAM, ampicillin sulbactam; CIP, ciprofloxacin; CHL, chloramphenicol; GEN, gentamicin;

NAL, naldixic acid; CEF, cefoxitin; SXT, trimethoprim; sulfamethoxazole; TET, tetracycline.

${ }^{\mathrm{d}} \mathrm{nt}$, not tested.

${ }^{e}$ According to the inhibition halos of the National Committee for Clinical Laboratory Standards for Antimicrobial Disk Susceptibility. 
association with other CFs, especially with CFA/I and the CFA/II group (CS1, CS2 and CS3). CS21 was detected by multiplex PCR in 10 strains but was only detected by phenotypic dot blot test in four of the strains. The pattern of phenotypically silent CS21 has previously been reported in Bolivian and Bangladeshi strains by us. ${ }^{14}$

When analyzing the serogroups of the ETEC strains, we found that they belonged to a diverse set of $\mathrm{O}$ groups (Table 1). Of these serogroups, O6, O8, O78, O114, O120, O148, O153 and O159 have frequently been associated with ETEC in previous studies ${ }^{18-20}$ and these 8 O-groups were detected in 26 of the 43 ETEC strains. A small number of additional strains were of $\mathrm{O}$ serogroups that have infrequently been detected in ETEC strains, namely, O1, $\mathrm{O} 41$ and $\mathrm{O} 21 .{ }^{19}$ The remaining serogroups $\mathrm{O} 34$ and $\mathrm{O} 174$ have to our knowledge not previously been described for any category of diarrheagenic E. coli. The strains that had O groups commonly found in ETEC were statistically more often $\mathrm{CF}$ positive than strains that either possessed an $\mathrm{O}$ serogroup not commonly found in ETEC or were nontypeable $(\mathrm{p}<0.0070)$. An $\mathrm{H}$ flagellar antigen was detected in 31 strains. The most common $\mathrm{H}$-antigen was $\mathrm{H} 9(\mathrm{n}=9)$; eight of these strains were $\mathrm{O} 8$ serogroup and six of these strains were O8:H9 LT/CS17 which is a common ETEC phenotype and probably constituted a clone that circulated in Bolivia from 2002 to 2005. Other common $\mathrm{H}$-antigens were H16 $(\mathrm{n}=4)$, all of which were O6: H16, H40 (n = 5) and $\mathrm{H} 45(\mathrm{n}=2)$.

The results of the antimicrobial susceptibility of the ETEC strains are shown in Table 1. Several of the strains were resistant to many antimicrobial drugs. The highest resistance rate was found for ampicillin $(53.5 \%$; $=23)$, followed by ampicillin-sulbactam $(46.5 \% ; \mathrm{n}=20)$, trimethoprim-sulfamethoxazole $(32.5 \% ; \mathrm{n}=14)$, tetracycline $(28 \%$; $\mathrm{n}=12)$ and chloramphenicol $(14 \% ; \mathrm{n}=6)$. Most strains were not resistant to nalidixic acid, gentamicin, and cefoxitin and all the tested strains were susceptible to ciprofloxacin.

\section{DISCUSSION}

In our analysis of the 43 ETEC strains from Bolivia we found an unusually high prevalence of LT-only strains. LT, ST and LT/ST strains worldwide often occur at comparable frequencies, ${ }^{19}$ but LT strains have previously been reported to be more common in South American surveys of ETEC prevalence than in surveys in Asia and Africa ${ }^{21,22}$ and recently an increase in LT strains also in Bangladesh was reported. ${ }^{23}$ The observed percentage of CF positive and negative strains is in agreement with other findings with approximately $2 / 3$ of the strains expressing known CFs. The most common CFs were CFA/I and CS17 and while CFA/I always is one of the most commonly detected CF in surveys worldwide the high prevalence of both CS17 and LT-only strains in this collection seemed to be due to an unusually high frequency of LT/CS17 strains. CS21 was commonly detected by PCR but less commonly by dot blot as reported earlier. ${ }^{14}$ These results may be due to the observed variability in the coding region for CS21.,24 The high prevalence of PCR positive CS21 strains among the Bolivian strains is in agreement with that observed in other countries in Asia and South America where CS21 frequencies between $19 \%$ to $36.5 \%$ have been reported in ETEC strain collections. ${ }^{25-27}$

There was a large variation of serotypes among the 43 ETEC strains. Unlike the genes for toxins and CFs, which are usually plasmid encoded, the $\mathrm{O}$ and $\mathrm{H}$ biosynthetic genes are chromosomal. ${ }^{28}$ This suggests a high degree of clonal diversity of disease-associated ETEC in this geographic area over a relatively short period of time. Notably, several of the serotypes detected were not those typically associated with ETEC. Since there is only evidence of protection against homologous $\mathrm{O}$ groups and no evidence that ETEC $\mathrm{O}$ - and $\mathrm{H}$-antigens are protective against heterologous serotypes, ${ }^{28-30}$ there would seem to be little to gain from incorporation of specific $\mathrm{O}$ - or $\mathrm{H}$-antigens into a vaccine against ETEC.

We found a relation between serotype, toxin and CF profile. Thus, O8:H9 strains commonly expressed LT and CS17 (6 strains) while the O78:HNM strain expressed LT, STh and CFA/I and carried the gene for CS21 (4 strains). We also detected three O6:H16 strains that expressed LT, STh and CS1 + CS3 + CS21 which has previously been reported to be the most frequently detected and widely distributed ETEC phenotype worldwide. ${ }^{19}$

ETEC strains that have identical toxin and CF profiles have been proposed to be genetically closely related. ${ }^{31,32}$ The results from this and other studies on ETEC serotypes support that strains with certain toxin and CF profiles often have certain $\mathrm{O}$ - and $\mathrm{H}$-antigens indicating that there might be a genetic relationship between strains with similar phenotypes regardless of where they are found in the world.

We found a high level of antibiotics resistance in the Bolivian ETEC strains (Table 1). It is reasonable that this multiresistance of ETEC might emerge to classical antibiotics such as ampicillin, tetracycline, and trimethoprimsulfamethoxazole ${ }^{33}$ since they have been widely used in Bolivia during the past few years. For instance the Integrated Management of Childhood Illness (AIEPI) manual recommends the use of trimethoprim-sulfamethoxazole as the first line antibiotic for the treatment of bloody diarrhea ${ }^{34}$ and tetracycline is prescribed for the treatment of different infectious diseases. Therefore, these antibiotics are widely used in medical settings in Bolivia.

Initially, doxycycline was recommended for the treatment of travelers' diarrhea but recently the fluoroquinolones have become the drug of choice. However, these drugs are not recommended for children and it should 
be taken into consideration that in spite of the minimal use of quinolones in Bolivia, we detected nalidixic acidresistant ETEC strains. The quinolone resistance in $E$. coli has mainly been associated with mutations in the gyrA and parC genes. Strains resistant to nalidixic acid are likely to have at least one mutation of the $g y r A$ gene. If quinolones are used as a first drug of choice for diarrhea in countries where the use of antibiotics is not regulated, a rapid emergence of quinolone resistance will likely occur. Therefore it is important to continue the surveillance of enteric bacterial pathogens for quinolone resistance. ${ }^{35}$ Rifaximin is a non-absorbable antimicrobial agent which has been shown to be effective for treatment of severe episodes of bacterial diarrhea in children in developed countries, ${ }^{36}$ and according to our results, resistance to ciprofloxacin is still uncommon in Bolivia.

Based on our results, we recommend a better control of prescribed antibiotics in Bolivia. Since most mild diarrhea cases are indeed successfully managed with oral rehydration therapy, our results further support that antimicrobial treatment should not be considered for treatment of ETEC diarrhea unless for more severe or persistent diarrhea cases. ${ }^{4}$

Finally, we found that there was a statistically significant correlation (Table 2) between expression of CFs and presence of antimicrobial resistance, since $82 \%(23 / 28)$ of the CF positive strains harbored antimicrobial resistance, in contrast to the $\mathrm{CF}$ negative strains which only were resistant in $47 \%$ (7/15) of the cases. This finding may suggest that resistance genes might be located on ETEC virulence plasmids. Presence of CFs has previously been found to correlate to disease ${ }^{37}$ and we found in this study that a high proportion of the ETEC strains that all were collected from hospitalized children expressed known CFs. Since these strains may also be more likely to also carry antibiotic resistance genes, our results further implicate that vaccination is a better solution than antimicrobial treatment.

Table 2. Analysis of the relation of expression of colonization factors and antimicrobial resistance in the selected etec strains. The association between antibiotic resistance and presence of $c f$ was considered to be statistically significant by the fishers exact test. $(P<0.0339)$

\begin{tabular}{lcc}
\hline & ${\text { Cf } \operatorname{pos}^{\mathrm{a}}(\mathrm{n}=28)}$ & cf neg $^{\mathrm{a}}(\mathrm{n}=15)$ \\
\hline $\begin{array}{l}\text { Antimicrobial } \\
\text { resistance }\end{array}$ & $23(82 \%)$ & $7(47 \%)$ \\
\hline $\begin{array}{l}\text { No antimicrobial } \\
\text { resistance }\end{array}$ & $5(\mathbf{1 8 \% )}$ & $8(53 \%)$ \\
\hline
\end{tabular}

${ }^{\mathrm{A}} \mathrm{cf}$ pos, colonization factor positive; cf neg, colonization factor negative

\section{ACKNOWLEDGMENTS}

This work is part of the UMSA-IBMB "Diarrheal Disease Project" supported by the Swedish Agency for Research Economic Cooperation (SIDA). Support was also obtained from the Swedish Research Council, grant no. 6X-09084, Ministerio de Ciencia e Innovación (Instituto de Salud Carlos III, Fondo de Investigación Sanitaria, REIPI- RD06/0008-1018 and PS09/01273) and Xunta de Galicia (07MRU036261PR, 09TAL007261PR, 2007/000044-0).

Claudia Rodas acknowledges the financial support from the Swedish Institute.

\section{REFERENCES}

1. Kosek M, Bern C, Guerrant RL. The magnitude of the global burden of diarrhoeal disease from studies published 19922000. Bull World Health Organ 2003; 81:197-204.

2. Parashar UD, Bresee JS, Glass RI. The global burden of diarrhoeal disease in children. Bull World Health Organ 2004; 81:236.

3. SNIS. Sistema Nacional de Información en Salud 2009. Bol Minis Salud Pub 2009.

4. Qadri F, Svennerholm AM, Faruque AS, Sack RB. Enterotoxigenic Escherichia coli in developing countries: epidemiology, microbiology, clinical features, treatment, and prevention. Clin Microbiol Rev 2005; 18:465-483.

5. Gaastra W, Svennerholm AM. Colonization factors of human enterotoxigenic Escherichia coli (ETEC). Trends Microbiol 1996; 4:444- 452.

6. Grewal H, Valvatine H, Bhan MK, van Dijk L, Gaastra W, Sommerfelt $\mathrm{H}$. A new putative fimbrial colonization factor, CS19, of human enterotoxigenic Escherichia coli. Infect Immun 1997; 65:507-513.

7. Pichel MG, Binsztein N, Qadri F, Girón JA. Type IV longus pilus of enterotoxigenic Escherichia coli: occurrence and association with toxin types and colonization factors among strains isolated in Argentina. J Clin Microbiol 2002; 40:694-697.

8. Gomez-Duarte OG, Chattopadhyay S, Weissman SJ, Giron JA, Kaper JB, Sokurenko EV. Genetic diversity of the gene cluster encoding longus, a type IV pilus of enterotoxigenic Escherichia coli. J Bacteriol 2007; 189:9145-9149.

9. López-Vidal Y, Calva JJ, Trujillo A et al. Enterotoxins and adhesins of enterotoxigenic Escherichia coli: are they risk factors for acute diarrhea in the community? J Infect Dis 1990; 162:442-447.

10. Walker RI, Steele D, Aguado T. Analysis of strategies to successfully vaccinate infants in developing countries against enterotoxigenic E. coli (ETEC) disease. Vac 2007; 25:2545-2566.

11. Svennerholm AM, Tobias J. Vaccines against enterotoxigenic Escherichia coli. Expert Rev Vaccines 2008; 7:795-804.

12. Pratts G, Mirelis B, Llovet T. Antibiotic resistance trends in enteropathogenic bacteria isolated in 1985-1987 and 1995-1998 in Barcelona. Antimicrob Agents Chemother 2000; 44:1140-5.

13. Sjöling Å, Wiklund G, Savarino SJ, Cohen DI, Svennerholm AM. Comparative analyzes of phenotypic and genotypic methods for detection of enterotoxigenic Escherichia coli toxins and colonization factors. J Clin Microbiol 2007; 45:3295-3301.

14. Rodas C, Iniguez V, Qadri F, Wiklund G, Svennerholm AM, Sjöling Å. Development of multiplex PCR assays for detection of enterotoxigenic Escherichia coli colonization factors and toxins. J Clinl Microbiol 2009; 47:1218-1220. 
15. Guineé PAM, Jansen H, Wadstrom T, Sellwood R. Escherichia coli associated with neonatal diarrhoea in piglets and calves. In: de Leeuw PW, Guinee PAM (eds) Laboratory diagnosis in neonatal calf and animal science, 13. The Netherlands, Martinus Nijhoff. 1981; 126-162.

16. Blanco J, González EA, Blanco M et al. Enterotoxigenic Escherichia coli associated with infant diarrhoea in Galicia, north-western Spain. J Med Microbiol 1991; 35:162-167.

17. National Committee for Clinical Laboratory Standards. Performance Standards for Antimicrobial Disk Susceptibility Tests-Eighth Edition: Approved Standard M2-A8. NCCLS, Villanova, PA, USA 2002.

18. Blanco J, Blanco M, González EA et al. Serotypes and colonization factors of enterotoxigenic Escherichia coli isolated in various countries. Eur J Epidemiol 1993; 9:489-496.

19. Wolf MK. Occurrence, distribution, and associations of $\mathrm{O}$ and $\mathrm{H}$ serogroups, colonization factor antigens, and toxins of enterotoxigenic Escherichia coli. Clin Microbiol Rev. 1997; 10:569-584.

20. Ansaruzzaman M, Bhuiyan NA, Begum YA et al. Characterization of enterotoxigenic Escherichia coli from diarrhoeal patients in Bangladesh using phenotyping and genetic profiling. J Med Microbiol 2007; 56:217-222.

21. Vicente AC, Teixeira LF, Iniguez-Rojas L et al. Outbreaks of cholera-like diarrhoea caused by enterotoxigenic Escherichia coli in the Brazilian Amazon Rainforest Trans R Soc Trop Med Hyg 2005; 99: 669-674.

22. Rivas M, Binsztein N, Basanta G et al. Antibody responses against Escherichia coli heat-labile toxin and colonization factor antigens I and II in Argentinean children. J Inf Dis 1995; 171: 1045-1049.

23. Harris AM, Chowdhury F, Begum YA et al. Shifting prevalence of major diarrheal pathogens in patients seeking hospital care during floods in 1998, 2004, and 2007 in Dhaka, Bangladesh. Am J Trop Med Hyg 2008; 79: 708-714.

24. Steinsland H, Valentiner-Branth P, Grewal HM, Gaastra W, Mølbak KK, Sommerfelt H. Development and evaluation of genotypic assays for the detection and characterization of enterotoxigenic Escherichia coli. Diag Microbiol Infec Dis 2003; 45:97-105.

25. Girón JA, Viboud GI, Sperandio V et al. Prevalence and association of the longus pilus structural gene (lngA) with colonization factor antigens, enterotoxin types, and serotypes of enterotoxigenic Escherichia coli. Infect Immun 1995; 63:4195-4198.
26. Gutiérrez-Cázarez Z, Qadri F, Albert MJ, Girón JA. Identification of enterotoxigenic Escherichia coli harboring longus type IV pilus gene by DNA amplification. J Clin Microbiol 2000; 38:1767-1771.

27. Nishimura LS, Girón JA, Nunes SL, Guth BE. Prevalence of enterotoxigenic Escherichia coli strains harboring the longus pilus gene in Brazil. J Clin Microbiol. 2002; 40:2606-2608.

28. Orskov F, Orskov I. Escherichia coli serotyping and disease in man and animals. Can J Microbiol 1992; 38:699-704.

29. Åhrén CM, Svennerholm AM. Synergistic protective effect of antibodies against Escherichia coli enterotoxin and colonization factor antigens. Infect Immun 1982; 38:74-79.

30. Reis MH, Matos DP, de Castro AF, Toledo MR, Trabulsi LR. Relationship among enterotoxigenic phenotypes, serotypes, and sources of strains in enterotoxigenic Escherichia coli. Infect Immun 1980; 28:24-27.

31. Sommerfelt $\mathrm{H}$, Steinsland $\mathrm{H}$, Grewal $\mathrm{H}$ et al. Colonization factors of enterotoxigenic Escherichia coli isolated from children in North India. J Infec Dis 1996; 174:768-776.

32. Pacheco A, Guth BE, Soares KC, Nishimura L, de Almeida DF, Ferreira LC. Random amplification of polymorphic DNA reveals serotype-specific clonal clusters among enterotoxigenic Escherichia coli strains isolated from humans. J Clin Microbiol 1997; 35:1521-1525.

33. Black RE, Levine MM, Clements ML, Cisneros L, Daya V. Treatment of experimentally induced enterotoxigenic Escherichia coli diarrhea with trimethoprim, trimethoprim-sulfamethoxazole, or placebo. Rev Infect Dis 1982; 4:540-545.

34. Benguigui Y. Atención Integrada a las Enfermedades Prevalentes de la Infancia. Bol Noticias IRA 2007; 33:2-5.

35. Vila J, Vargas M, Ruiz J. Quinolone resistance in Enterotoxigenic Escherichia coli causing diarrhea in travelers to India in comparison with other geographical areas. Antimicrob Agents Chemother 2000; 44:1731-33.

36. Frisari L, Viggiano V, Pelagalli M. An open, controlled study of two non-absorbable antibiotics for the oral treatment of paediatric infectious diarrhoea. Curr Med Res1997; 14:39-45.

37. Qadri F, Das SK, Faruque AS et al. Prevalence of toxin types and colonization factors in enterotoxigenic Escherichia coli isolated during a 2-year period from diarrheal patients in Bangladesh. J Clin Microbiol 2000; 38:27-31. 